\title{
Analytics and models for maritime logistics and systems
}

\author{
Kjetil Fagerholt ${ }^{1} \cdot$ Kap Hwan Kim ${ }^{2} \cdot$ Qiang Meng ${ }^{3}$. Julio César Góez ${ }^{4}$. \\ Frank Meisel $^{5} \cdot$ Magnus Stålhane $^{1}$
}

Published online: 14 June 2019

○) Springer Science+Business Media, LLC, part of Springer Nature 2019

Today's globalized operations post a challenge for most companies to achieve distribution networks that are flexible enough to adapt to the dynamic and growing markets. In this environment, decision makers often find themselves overwhelmed with this complexity. At the same time, these globalized operations generate an enormous amount of data about the movement of cargo around the world. This new wealth of data offers an enormous opportunity to optimize the maritime and logistics transportation industry to prevail over the challenges that the global scale operations bring. However, to take advantage of these opportunities decision makers need the right analytical tools and models suitable to exploit the opportunities big data is offering.

This special issue of the Flexible Services and Manufacturing (FSM) Journal aims to address corresponding challenges and explore the opportunities related to

Kjetil Fagerholt

kjetil.fagerholt@ntnu.no

Kap Hwan Kim

kapkim@pusan.ac.kr

Qiang Meng

ceemq@nus.edu.sg

Julio César Góez

julio.goez@nhh.no

Frank Meisel

meisel@bwl.uni-kiel.de

Magnus Stålhane

magnus.staalhane@ntnu.no

1 Department of Industrial Economics and Technology Management, Norwegian University of Science and Technology, Trondheim, Norway

2 Department of Industrial Engineering, Pusan National University, Busan, Korea

3 Department of Civil and Environmental Engineering, National University of Singapore, Singapore, Singapore

4 Department of Business and Management, Norwegian School of Ecnomics, Bergen, Norway

5 Faculty of Business, Economics, and Social Science, Christian-Albrechts-University Kiel, Kiel, Germany 
ocean transportation, port operations, and hinterland logistics. The papers are an outcome of the 7th International Conference on Logistics and Maritime Systems (LOGMS) that was held in Bergen, Norway, in August 2017. There were 29 submissions for this special issue. After a thorough peer-review according to the standards of the FSM journal, the following nine papers were accepted for publication.

\section{Papers in the special issue}

The paper of Giovannini and Psaraftis (2019) investigates a profit maximizing liner shipping problem, which is to decide on the number of ships to deploy on a route and on the ship speed along each leg of the route. Contrasting other papers in this field, also service frequency is a decision here, which allows to adjust the frequency of port calls to the market demand. Experiments show that this flexibility can be used to either reduce fuel cost or to increase the served demand depending on the market conditions faced. The impact of these decisions on $\mathrm{CO}_{2}$ emissions is examined too.

In Holm et al. (2019), a liner network design problem is considered where cargo can be transshipped among ships at sea. In this problem, daughter ships serve local ports along a cost line and a mother ship carries cargo from one region to the next. Transshipment of cargo takes place at sea in order to minimize total charter cost, bunker cost, and port cost. The problem is solved by a two-step approach that first generates candidate routes and then selects the best routes through a path flow model. A case study from Western Norway illustrates that this approach can be used for determining optimal routes and fleet compositions.

Tierney et al. (2019) present three models for designing a liner shipping service. The models differ in assumption regarding ship speeds (given input or a decision) and bounded transit times for the cargo. All three models contain chance constraints to ensure on-time arrival of vessels at ports with a given service level. The authors conduct an empirical analysis of real-world ship travel times to derive probability distributions for the specification of the chance constraints. Simulation experiments for numerous real liner shipping routes reveal that late arrivals of ships are significantly reduced if services are designed through the proposed models.

The paper of Wang and Meng (2019) presents a methodology for forecasting the container slot booking of a liner shipping service. More precisely, the authors use piecewise linear regression, autoregression, and artificial neural networks to forecast the number of containers to be transported between two continents through the long-haul leg of an intercontinental liner service. Using real-case booking data, it is shown that a combination of the three methods leads to forecasts of satisfactory precision.

Diz et al. (2019) consider a maritime inventory routing problem that determines the routings of ships and cargoes such that inventory levels at ports stay within given limits. The focus of the paper is on the development of a robust optimization model that can cope with operational delays to the port service times. Decision makers can use this approach to trade off the risks of violating the inventory limits against the 
observed transportation costs. A case study for a Brazilian petroleum company illustrates this trade-off for a real-world example.

Jovanovic et al. (2019) investigate the block relocation problem, which is to retrieve containers from a yard bay of a container terminal in an order that fits to the intended stowage plan of the served ship. The objective is to minimize the number of relocations of those containers that obstruct access to the next container to load onto the ship. The authors present a Greedy Randomized Adaptive Search Procedure that combines various heuristic concepts. Experiments show that this method significantly outperforms existing methods for the considered problem.

The paper of Yi et al. (2019) presents a methodology that schedules appointments for trucks that deliver or retrieve containers at a port. The goal of the appointment system is to alleviate traffic congestion especially in peak hours. The authors propose a non-linear optimization model and a scheduling heuristic that minimize the corresponding cost of the trucking companies. The heuristic delivers near-optimal solutions and clearly outperforms competing methods that were proposed by earlier research.

Pérez Rivera and Mes (2019) integrate the scheduling of drayage operations and long-haul transports for conducting freight flows in a terminal network. While drayage operations are done using trucks, long-haul transports are performed by trains or barges. Stochastic arrivals of vehicles and flexible terminal assignment are further aspects considered in this paper. For tackling the combined problem, the authors solve an optimization model for the drayage operations and a Markov Decision Process model for the long-haul transportation. Experiments show that the integration can lead to substantial cost savings.

$\mathrm{Hu}$ et al. (2019) investigate the transportation of containers between different terminals of a port and towards the hinterland. For this purpose, containers from various terminals are first consolidated in a rail yard and then carried by train to terminals in the hinterland. The paper presents an optimization model that includes various operational aspects of the container handling and the vehicle operations. The objective is to minimize the number of containers that are not delivered on time. A rolling horizon framework is proposed for accelerating the solution process. A network inspired by the Maasvlakte terminals in Rotterdam is used for analyzing the potentials of the proposed approach.

\section{Concluding remarks}

We congratulate all authors to their excellent research and we thank all reviewers for their helpful comments and their timely refereeing.

\section{References}

Diz GSdS, Hamacher S, Oliveira F (2019) A robust optimization model for the maritime inventory routing problem. Flex Serv Manuf J. https://doi.org/10.1007/s10696-018-9327-9

Giovannini M, Psaraftis HN (2019) The profit maximizing liner shipping problem with flexible frequencies: logistical and environmental considerations. Flex Serv Manuf J. https://doi.org/10.1007/s1069 6-018-9308-z 
Holm MB, Medbøen CAB, Fagerholt K, Schütz P (2019) Shortsea liner network design with transhipments at sea: a case study from western norway. Flex Serv Manuf J. https://doi.org/10.1007/s10696-018-9317-y

Hu Q, Wiegmans B, Corman F, Lodewijks G (2019) Integration of inter-terminal transport and hinterland rail transport. Flex Serv Manuf J. https://doi.org/10.1007/s10696-019-09345-8

Jovanovic R, Tanaka S, Nishi T, Voß S (2019) A GRASP approach for solving the blocks relocation problem with stowage plan. Flex Serv Manuf J. https://doi.org/10.1007/s10696-018-9320-3

Pérez Rivera AE, Mes MRK (2019) Integrated scheduling of drayage and long-haul operations in synchromodal transport. Flex Serv Manuf J. https://doi.org/10.1007/s10696-019-09336-9

Tierney K, Ehmke JF, Campbell AM, Müller D (2019) Liner shipping single service design problem with arrival time service levels. Flex Serv Manuf J. https://doi.org/10.1007/s10696-018-9325-y

Wang Y, Meng Q (2019) Integrated method for forecasting container slot booking in intercontinental liner shipping service. Flex Serv Manuf J. https://doi.org/10.1007/s10696-018-9324-z

Yi S, Scholz-Reiter B, Kim T, Kim KH (2019) Scheduling appointments for container truck arrivals considering their effects on congestion. Flex Serv Manuf J. https://doi.org/10.1007/s10696-019-09333-y

Publisher's Note Springer Nature remains neutral with regard to jurisdictional claims in published maps and institutional affiliations.

Kjetil Fagerholt is a Professor in Operations Research at the Norwegian University of Science and Technology, Department of Industrial Economics and Technology Management. He also holds positions as Adjunct Professor at the Department of Marine Technology at the same university. His main research interest is on developing and applying Operations Research models and methods on planning problems in maritime transportation. He has published around 100 papers in international peer-reviewed journals. He is Associate Editor for Transportation Science and Flexible Services \& Manufacturing.

Kap Hwan Kim is working at the Department of Industrial Engineering of Pusan National University. He studied at the Seoul National University (Bachelor) and the Korea Advanced Institute of Science and Technology (Master, Ph.D.). He was the president of the Korean Institute of Industrial Engineers. His research is focused on the design and operational problems of container terminals.

Qiang Meng is a Professor in the Department of Civil and Environmental Engineering at National University of Singapore. His main research includes transportation network modelling and optimization, shipping and intermodal freight transportation analysis, and quantitative risk assessment of transport operations. He has published more than 180 articles in the leading transportation and logistics journals such as Transportation Research Part B, Transportation Research Part E and Transportation Science. He is the Co-Editor-in-Chief of Transportation Research Part E, and Associate Editor of Transportation Research Part B.

Julio César Góez is an Assistant Professor at NHH Norwegian School of Economics, Norway. He holds a Ph.D. in Industrial Engineering from Lehigh University. His research interests revolves around integer optimization and its applications for the planning and design of logistic networks.

Frank Meisel is a Professor of Supply Chain Management at the University of Kiel, Germany. He holds a Diploma Degree in Transportation Engineering from the Technical University of Dresden and a Ph.D. in Business Administration from Martin Luther University, Halle-Wittenberg. His research interests include maritime logistics, sustainable transportation management, and supply chain management.

Magnus Stålhane is an Associate Professor in Operations Research at the Department of Industrial Economics and Technology Management at the Norwegian University of Science and Technology (NTNU). He holds a MSc in Industrial Engineering and a Ph.D. in Operations Research from NTNU. His research interests include optimization of logistics problems within vehicle routing and maritime transportation. 